\title{
Curcumin: The Molecular Mechanisms of Action in Inflammation and Cell Death during Kainate-Induced Epileptogenesis
}

\author{
Yow Hui-Yin', Nurulumi Ahmad², Norazrina Azmi², Mohd Makmor-Bakry²* \\ ${ }^{1}$ School of Pharmacy, Faculty of Health and Medical Sciences, Taylor's University Lakeside Campus, Subang Jaya, MALAYSIA. \\ ${ }^{2}$ Faculty of Pharmacy, Universiti Kebangsaan Malaysia, Kuala Lumpur, MALAYSIA.
}

\begin{abstract}
Background: Recent preclinical studies demonstrated the potential antiepileptogenic effect of curcumin. Its molecular pathways in modulating epileptogenesis remain unclear. Objectives: This study investigated the epileptogenic processes induced by kainic acid (KA) and to investigate the antiepileptogenic pathways associated with curcumin therapy. Methods: A single dose of KA $10 \mathrm{mg} / \mathrm{kg}$ was used to induce a convulsive status epilepticus in female Wistar rats. After one week of curcumin treatment, gene expression profiling by using microarray was conducted on hippocampal tissues. A set of differential expression changes was determined based on criteria of dual fold change in either direction and $p<0.05$, whereas gene annotation and pathway analysis had been performed using Database for Annotation, Visualization and Integrated Discovery software. Results: A number of genes significantly altered in expression during KAinduced epileptogenesis. Inflammation and immune response were the prominent overexpressed processes induced by KA. Genes of cell surface molecule (CD74), cytokines and immune response related genes (IL18, IFNGR1, C3, RT1-BA) were significantly up-regulated. Changes of genes related to cell death and gliosis (NCSTN, CTSH) were also observed in KA-induced epileptogenesis. This study revealed that curcumin modulated the epileptogenic process by up-regulating genes related to antiinflammatory cytokines (IL1ORB, CXCL16, and CXCL17) and protecting against cell loss by up-regulating NCSTN. It was also likely to exert neuroprotective effects through the up-regulation of CX3CL1 and CXCL16. Conclusion: This study provides novel insights into the mechanisms of curcumin in epileptic brain, which form the basis for future studies looking into its molecular pathway as an antiepileptogenic agent.
\end{abstract}

Key words: Epileptogenesis, Curcumin, Kainic acid, Gene expression, Anti-epileptogenic, Temporal lobe epilepsy.

\section{INTRODUCTION}

Temporal lobe epilepsy (TLE) is the most common and difficult-to-treat type of partial epilepsy. ${ }^{1}$ There are up to $40 \%$ of epileptic patients that are resistant to current antiepileptic drugs and remain in uncontrolled state. $^{2}$ Current antiepileptic drugs only provide symptomatic relief by suppressing seizures, with none of them exerting significant effect in preventing or inhibiting the progression of epilepsy. ${ }^{3}$ However, studies suggest that they have functions other than just suppression of excitability. The neuroprotective effects of 20 AEDs currently in use or being investigated in Phase II - III clinical trials for treatment of epilepsy are reviewed. Data analyses is complicated by several factors. Firstly, the available data on the neuroprotective effects of different AEDs varies largely. Secondly, most of the evidence demonstrating neuroprotective effects comes from stroke models and it is uncertain whether these data can be extrapolated to other conditions, such as status epilepticus (SE). Therefore, in recent years, epilepsy research has changed its focus from targeting control of seizures to
Submission Date: 29-07-2017; Revision Date: 25-09-2017; Accepted Date: 10-01-2018

DOI: 10.5530/ijper.52.1.4 Correspondence: Dr. Mohd Makmor-Bakry, Faculty of Pharmacy, University Kebangsaan Malaysia, Jalan Raja Muda Abdul Aziz, 50300 Kuala Lumpur, MALAYSIA. Phone no: 60326983271 E-mail: mohdclinpharm@ ukm.edu.my

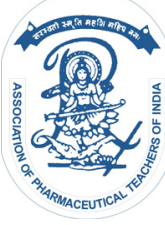

www.ijper.org 
strategies for prevention and cure of epilepsy. ${ }^{4}$ Animal models play a crucial role in discovering the potential agents with antiepileptogenic properties. Post-status epilepticus (SE) with spontaneous recurrent seizures models have been recommended for studying TLE. ${ }^{5}$ This is attributed to the characteristics of the model with a latency period followed by spontaneous recurrent seizures, brain lesions produced and clinical behavioral alterations that resemble the TLE. ${ }^{6}$ On the other hand, this model has been recommended as useful tool for studying mechanism of epileptogenesis and discovering antiepileptogenic treatment. ${ }^{7}$

Curcumin is the main active constituent extracted from rhizome of the plant Curcuma longa L. (Zingiberaceae). Recent preclinical studies demonstrated that curcumin may exhibit promising anticonvulsant effect, ${ }^{8}$ as well as potential antiepileptogenic effect. ${ }^{910}$ It also has been shown to possess protective effects in ameliorating cognitive impairments and anxiety in epileptic animals. ${ }^{9,11}$ These benefits highlighted curcumin as a potential antiepileptogenic agent for controlling the epilepsy and psychiatric-related comorbidities. Nevertheless, the molecular mechanisms of curcumin that modulate the epileptogenesis are poorly understood.

The development of molecular biological technologies allows the large scale analysis of gene expression in epilepsy research. Epileptic insults may cause numerous neurobiological changes that lead to epileptogenesis and these changes might be attributed to alteration in gene expressions. ${ }^{12}$ The DNA microarrays technique has been used as tools to identify the cellular and molecular processes that involved in epileptogenesis by studying the gene expression profiles. ${ }^{12,13}$ The origin of seizure activity typically involves the hippocampal formation, which displays major neuropathological features, described with the term hippocampal sclerosis (HS). This technique enables simultaneous analysis of thousands of genes and provides insight into gene expression profiles in a wide range of studies. ${ }^{14}$ Consistent with the development of this genomic approach, several studies demonstrated that a number of genes are involved in the epileptogenesis process. ${ }^{15,16,17,18}$ We investigated gene expression during epileptogenesis in the rat. RNA was obtained from hippocampus of brain.

Therefore, this study employed the microarray technique to understand the cellular and molecular mechanisms that involved in epileptogenesis process in kainateinduced epileptic rat model and identifying the specific genes that involved in this process.

This study also investigated the molecular pathways of curcumin in modulating the epileptogenesis.

\section{MATERIALS AND METHODS}

\section{Animals}

A total of 40 female Wistar rats weighing $200-220 \mathrm{~g}$ were purchased. They were kept under controlled environment conditions $\left(23^{\circ} \mathrm{C} \pm 1^{\circ} \mathrm{C}, 50-60 \%\right.$ humidity, $12 \mathrm{~h}$ light/12 $\mathrm{h}$ dark cycle) with free access to food and water. The rats were housed in groups of three and allowed to acclimatize for 1 week before the experiment. All experimental procedures were carried out during the light phase. All animal care and handling were conducted in accordance with approved use by Animal Ethics Committee of university (UKMAEC approval number: FF/2013/MOHD/31-JAN./491-MARCH-2013APRIL-2015).

\section{Seizure induction and treatments administration}

For SE induction, the rats were intraperitoneally injected with a single dose of $10 \mathrm{mg} / \mathrm{kg}$ kainic acid (KA) (SigmaAldrich, St. Louis, USA) which dissolved in isotonic saline. In the control group, the vehicle (saline) injection was given intraperitoneally at similar volume as KAinduced group. After the KA or vehicle injection, the rats were returned back to the cages and monitored behaviorally for $6 \mathrm{~h}$. Seizure severity will be scored according to Racine (1972): 1, mouth and facial movement; 2, head nodding; 3 , forelimb clonus; 4, rearing; 5 , rearing and falling accompanied by generalized clonic seizures. Rats that achieved stage 4 or stage 5 of SE were randomly distributed to group 2 and 3 . Each group consisted of a minimum of six animals and treatment given was as following:

Group 1: IP DMSO 50\% treated/without seizure induction

Group 2: IP DMSO 50\% treated/with seizure induction Group 3: IP curcumin-treated/with seizure induction

The treatment was initiated on the day after the seizure induction and terminated after 7 days of treatment. Curcumin ( $\geq 94 \%$ curcuminoid content, $\geq 80 \%$ curcumin; Sigma-Aldrich, St. Louis, USA) was prepared freshly by suspending in 50\% DMSO and administered at dose of $100 \mathrm{mg} / \mathrm{kg} /$ day. The vehicle, $50 \%$ DMSO was administered intraperitoneally for group 1 and 2, the control groups.

\section{Tissue sampling and RNA extraction}

After the treatment, six rats were selected from each group for decapitation and both hippocampi were dissected. Approximately $75 \mathrm{mg}$ of the tissue sample from each rat was used for RNA purification immediately using RNeasy ${ }^{\circledR}$ Microarray Tissue Mini Kit (Qiagen, Hilden, Germany). The concentration and purity of 
RNA samples were determined by measuring the absorbance of $260 \mathrm{~nm}$ and $260 \mathrm{~nm} / 280 \mathrm{~nm}$ absorbance ratios, respectively with microplate reader Infinite ${ }^{\circledR}$ M200 PRO NanoQuant (Tecan, Grodig, Austria). The RNA quality was further assayed and ensured by gel electrophoresis $\left(\mathrm{E}-\mathrm{Gel}^{\mathbb{}}{ }^{\mathbb{2}}\right.$, Invitrogen, Kiryat Shmona, Israel) and Agilent 2100 Bioanalyzer (Agilent, Palo Alto, CA, USA). Samples with RNA integrity number more than 7 were included for the microarray analysis.

\section{Affymetrix Genechip processing}

A volume of $200 \mathrm{ng}$ of total RNA from each sample was used as template to generate amplified cDNA using Applause ${ }^{\circledR}$ W'T-Amp plus ST System (NuGen Technologies, San Carlos, USA). The Gene Chip ${ }^{\circledR}$ Rat Gene 2.0 ST Array (Affymetrix, San Carlos, USA), which is an oligonucleotide array that interrogates more than 17,000 well-annotated genes with more than 610,400 distinct probes, was used in this study. As per Affymetrix's protocol, hybridization mixes were prepared and put onto chips which were then washed, stained and scanned by using Affymetrix GeneChip Fluidics Workstation and Genechip ${ }^{\circledR}$ Scanner 3000.

\section{Microarray data analysis}

The expression levels for all probe sets were calculated with Robust Multichip Average algorithm by using Affymetrix ${ }^{\circledR}$ Expression Console 1.3 Software to normalize overall intensities between different arrays. Data transformations ( $\log 2$ conversion), selection and statistical analyses were performed with Affymetrix ${ }^{\circledR}$ Transcriptome Analysis Console software. A set of differential expression changes was determined by dual fold change in either direction or at least $\mathrm{p}<0.05$ using one way ANOVA (unpaired) for a significant difference. The dataset of the significantly altered genes was imported to the Database for Annotation, Visualization and Integrated Discovery (DAVID) v6.7 (available at http:// david.abcc.ncifcrf.gov/) for bioinformatics analysis. ${ }^{20}$

\section{Real-time quantitative polymerase chain reaction analysis}

For microarray data validation, real-time quantitative polymerase chain reaction (qPCR) analysis was performed using RNA obtained from the same hippocampal tissues as used in array experiment. The concentration and purity of RNA samples were determined by spectrophotometry, electrophoresis and bioanalyzer. A volume of $0.5 \mu \mathrm{g}$ total RNA was reverse-transcribed into cDNA by using RT ${ }^{2}$ First Strand kit (Qiagen, Germantown, USA). The PCR primers used were RT2 ${ }^{2}$ PCR Primer Assays from Qiagen (Germantown, USA). Every primer pair underwent through the wet-lab validation and evaluated in term of specificity and efficiency. The primer assays contained a mix of forward and reverse primers, $10 \mu \mathrm{M}$ each, with high PCR efficiency (100\% amplification efficiency). Three highly expressed genes (i.e. ITGAM, CXCL16, and CD74) in the array analysis were selected and analyzed in qPCR as listed in Table 1. Expression levels of the reference genes beta-actin, (ACTB) and TATA box binding protein (TBP) were also tested for normalization of the expression level of the target gene. Samples were run in triplicate in a $25 \mu \mathrm{l}$ reaction with $\mathrm{RT}^{2}$ SYBR ${ }^{\circledR}$ Green ROX qPCR Master mix (Qiagen, Germantown, USA) using Master cycler ${ }^{\circledR}$ ep realple $x^{4}$ S (Eppendorf, Hamburg, Germany). The SYBR Green Master mix contained PCR buffer, HotStart DNA Taq polymerase, dNTPs mix, SYBR Green dye and ROX passive reference dye. A reaction mix was prepared on ice in a $0.2 \mathrm{ml}$ clear, low profile thin wall PCR strip with flat ultra-clear cap sealing (Bio-Rad Laboratories, Hemel Hempstead, UK) for each sample as following: $12.5 \mu \mathrm{l}$ of SYBR Green Master mix, $1 \mu \mathrm{l}$ of cDNA, $1 \mu \mathrm{l}$ of $10 \mu \mathrm{M}$ primers and RNase-free water adjusted to final volume of $25 \mu \mathrm{l}$. The reaction mix was performed in thermal cycling conditions at $95{ }^{\circ} \mathrm{C}$ for $10 \mathrm{~min}$ and followed by 40 cycles at $95^{\circ} \mathrm{C}$ for $15 \mathrm{sec}$ and $60{ }^{\circ} \mathrm{C}$ for $1 \mathrm{~min}$. The temperature ramp rate was set at $26 \%$. The fluorescent products were measured at $60^{\circ} \mathrm{C}$ after each

\begin{tabular}{|c|c|c|c|c|}
\hline Gene symbol & Gene description & RefSeq accession no.* & Band size (bp) & $\begin{array}{l}\text { Reference } \\
\text { position** }\end{array}$ \\
\hline ITGAM & Integrin, alpha M & NM_012711.1 & 99 & 3359 \\
\hline CXCL16 & Chemokine (C-X-C motif) ligand 16 & NM_00101748.1 & 116 & 910 \\
\hline CD74 & $\begin{array}{l}\text { Cd74 molecule, major histocompatibility complex, } \\
\text { class II invariant chain }\end{array}$ & NM_013069.2 & 82 & 612 \\
\hline ACTB & Actin, beta & NM_031144.3 & 127 & 1039 \\
\hline TBP & TATA box binding protein & NM_001004198.1 & 172 & 514 \\
\hline
\end{tabular}

* sequence used to design the primer.

** position of the amplicon in the RefSeq sequence. 


\begin{tabular}{|c|c|c|c|c|}
\hline Group & $\begin{array}{l}\text { Rat used for gene } \\
\text { expression analysis }\end{array}$ & $\begin{array}{l}\text { Seizure severity } \\
\text { (stage) }\end{array}$ & SE duration (min) & Survival time (day) \\
\hline \multicolumn{5}{|c|}{ Group 2 (KA-DMSO) } \\
\hline Rat 1 & yes & 5 & 90 & 14 \\
\hline Rat 2 & yes & 4 & - & 14 \\
\hline Rat 3 & yes & 4 & - & 14 \\
\hline Rat 4 & yes & 5 & 135 & 14 \\
\hline Rat 5 & no & 5 & 205 & 2 \\
\hline Rat 6 & no & 5 & 96 & 1 \\
\hline Rat 7 & no & 5 & 123 & 4 \\
\hline Rat 8 & yes & 5 & 120 & 14 \\
\hline Rat 9 & yes & 4 & - & 14 \\
\hline Mean \pm S.D. & $n=6$ & $4.67 \pm 0.50$ & $128.17 \pm 41.32$ & $10.11 \pm 5.88$ \\
\hline \multicolumn{5}{|c|}{ Group 3 (KA-CUR) } \\
\hline Rat 1 & yes & 4 & - & 14 \\
\hline Rat 2 & no & 5 & 262 & 1 \\
\hline Rat 3 & no & 5 & 111 & 3 \\
\hline Rat 4 & no & 5 & 116 & 1 \\
\hline Rat 5 & no & 5 & 242 & 4 \\
\hline Rat 6 & yes & 5 & 113 & 14 \\
\hline Rat 7 & yes & 5 & 224 & 14 \\
\hline Rat 8 & yes & 5 & 146 & 14 \\
\hline Rat 9 & yes & 4 & - & 14 \\
\hline Rat 10 & yes & 5 & 216 & 14 \\
\hline Mean \pm S.D. & $n=6$ & $4.80 \pm 0.42$ & $178.75 \pm 63.57$ & $9.30 \pm 6.13$ \\
\hline
\end{tabular}

aStage 1, mouth and facial movement; Stage 2, head nodding; Stage 3, forelimb clonus; Stage 4, rearing; Stage 5 , rearing and falling. $n=$ number of animals per group. KA, kainic acid; DMSO, dimethyl sulfoxide; CUR, curcumin.

cycle. A melt curve was performed after amplification at $95{ }^{\circ} \mathrm{C}$ for $15 \mathrm{sec}$, followed by holding at $60{ }^{\circ} \mathrm{C}$ for $15 \mathrm{sec}$ and gradually increased the temperature to $95^{\circ} \mathrm{C}$ for $15 \mathrm{sec}$. A negative control without cDNA template (i.e. no template control) was run parallel in duplicate to assess the specificity of the reaction and detect contamination. For no template control, the cDNA template was replaced by $1 \mu \mathrm{l}$ of RNase-free water.

\section{RESULTS}

\section{Severity of status epilepticus}

Thirty-four rats were given KA, of which 28 (82.35\%) rats developed stage $4(\mathrm{n}=8)$ or stage $5(\mathrm{n}=20)$ of SE, which lasting for $169.30 \pm 53.36 \mathrm{~min}$, but only 19 $(67.86 \%)$ survived until completion of treatment. Those rats, which failed to achieve stage 4 or 5 (stage $1, \mathrm{n}=2$; stage $2, \mathrm{n}=3$; stage $3, \mathrm{n}=1$ ) and died ( $\mathrm{n}=9$ ) were excluded for the subsequent analysis. There was no seizure activity observed in saline-induced control group. The characteristic of the kainate-induced epileptic rats in respective group had been shown in Table 2.

Systemic administration of KA produced a successive behavioral alterations in sequential. The mean latency to onset of seizure with staring and motionless (stage 1) was $6.18 \pm 3.98 \mathrm{~min}$. This behavior was followed by incidences of wet dog shakes accompanied with repetitive motor activities included head nodding, twitching of vibrissae and blinking (stage 2), which occurred $34.75 \pm 11.69 \mathrm{~min}$ after administration. After $61.90 \pm$ $25.22 \mathrm{~min}$, this behavior progressed to limbic seizures involved forelimb clonus (stage 3). The seizures progressively involved more severe limbic convulsions with rearing (stage 4), bilateral clonus of the upper limbs and loss of balance accompanied by generalized clonic seizures (stage 5), which started approximately one and half $h$ after $\mathrm{KA}$ injection and continued for two to three $\mathrm{h}$.

\section{Gene expression profile}

From the PCA analysis, one sample, which was deviated the most from respective group, had been excluded. 
Table 3: The total number of up-regulated and down-regulated genes by respective treatment.

\begin{tabular}{|c|c|c|}
\hline Number of genes & Up-regulated $^{\text {a }}$ & Down-regulated $^{\text {a }}$ \\
\hline Kainic acid & 5 & 10 \\
\hline Curcumin & 61 & 25 \\
\hline
\end{tabular}

The effect of kainic acid referred to genes expression that altered by kainic acid, in comparison to the control group (KA-DMSO versus saline-DMSO group). The effect for curcumin was determined by genes that altered expression in curcumin-treated epileptic rats, in comparison to the kainic acid treated group (i.e. KA-CUR

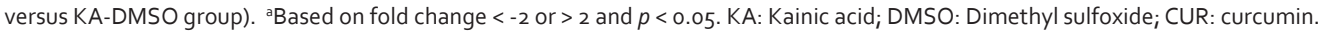

The samples included for further analysis was 20, which was 5 samples per group. Data filtering identified 36,685 out of 220,231 probe sets $(17 \%)$ reached informative signal intensity values on the array. A list of 370 genes was differentially expressed based on fold change more than two in either direction or $\mathrm{p}$ value less than 0.05 by ANOVA analysis. Among the genes, the total number of genes up-regulated and down-regulated by respective treatment was showed in Table 3 . Figure 1 shows the hierarchical clustering of differentially expressed genes for respective treatment.

\section{Gene annotation and pathway analysis}

DAVID analysis was used to classify the identified genes into three classes of processes, namely biological processes, molecular function and cellular component, (a)

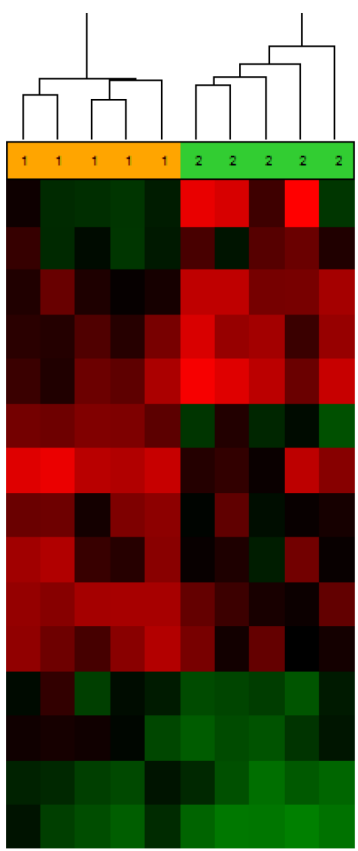

(b)

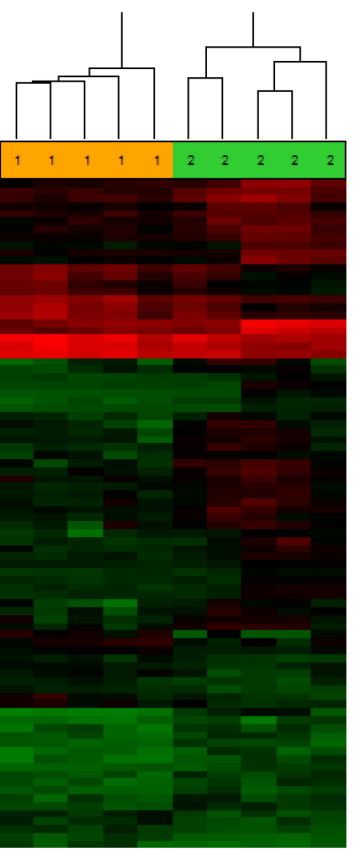

Figure 1: The hierrarhical clustering of differentially expressed genes for respective treatment. (a) Effect of kainic acid on gene expression (1: Saline-DMSO; 2: KA-DMSO). (b) Effect of curcumin on gene expression (1: KA-DMSO; 2: KA-CUR). A clear separation between the groups which indicated that the treatment specimens have own characteristic profile. Each column represents expression of a single sample. Each row represents a single gene expression (green colour: down-regulated; red colour: up-regulated). based on Gene Ontology (GO) classification. EASE score was used to determine the gene-term enrichment significance with a modified Fisher's exact test. ${ }^{21}$ EASE score that less than 0.05 , suggested that the gene-term is significantly more enriched.

\section{Gene associated with inflammation and immune response}

There were many genes that associated with immune response identified in kainate or curcumin treatment (Table 4). Treatment of KA only up-regulated the gene of cell surface molecule, CD74 with fold changes more than two times. Simultaneously, KA also caused significant over-expression of some immune response related genes, including IL18, IFNGR1, C3 and RT1BA with fold change less than 2. Curcumin treatment increased the gene expression of chemokines, such as CX3CL1, CXCL16, CXCL17 and CX3CR1. Immunerelated genes that over-expressed significantly by curcumin treatment with fold change less than 2 times were complement receptor, C3AR1 and interleukin 10 receptor, IL10RB.

\section{Gene associated with cell death}

Curcumin treated group was found to up-regulated nicastrin significantly (NCSTN; 4 fold increased). Contrastly, nicastrin (NCSTN; 2 fold decreased) was down-regulated significantly after kainate treatment. Cathepsins, lysosomal proteases were also found to be played an important role in neurodegenerative diseases (Zhang et al. 2009). KA treatment up-regulated the cathepsin H (CTSH; 1.28 fold increased), while curcumin treatment up-regulated the cathepsin A and D (CTSA, CTSD; 2 fold increased respectively).

\section{Gene associated with gliosis}

Vimentin (VIM), the intermediate filaments presented in astrocytes had been found to be over-expressed in kainite-treated group, with 1.9 fold increased.

\section{QPCR validation}

To validate the result of microarray, the genes expression of three selected genes that highly changed on the array and two reference genes (ACTB, TBP) were investigated by using qPCR. The gene expression patterns in qPCR 


\begin{tabular}{|c|c|c|c|}
\hline \multirow[t]{2}{*}{ Gene symbol } & \multirow[t]{2}{*}{ Gene name } & \multicolumn{2}{|c|}{ Fold change } \\
\hline & & KA & CUR \\
\hline \multicolumn{4}{|l|}{ hemokines } \\
\hline $\mathrm{XCL} 16$ & chemokine (C-X-C motif) ligand 16 & & 3.85 \\
\hline X3CR1 & chemokine (C-X3-C motif) receptor 1 & & 3.49 \\
\hline X3CL1 & chemokine (C-X3-C motif) ligand 1 & & 2.45 \\
\hline $\mathrm{XCL} 17$ & chemokine (C-X-C motif) ligand 17 & & 2.87 \\
\hline \multicolumn{4}{|l|}{ terleukins } \\
\hline 18 & interleukin 18 & 1.21 & \\
\hline 10RB & interleukin 10 receptor, beta & & 1.70 \\
\hline \multicolumn{4}{|l|}{ ther cytokines } \\
\hline ENGR1 & interferon gamma receptor 1 & 1.18 & \\
\hline \multicolumn{4}{|c|}{ lajor histocompatibility complex } \\
\hline T1-BA & RT1 class II, locus Ba & 1.27 & \\
\hline D74 & $\begin{array}{l}\text { Cd74 molecule, major histocompatibility } \\
\text { complex, class II invariant chain }\end{array}$ & 2.18 & \\
\hline \multicolumn{4}{|c|}{ omplement components } \\
\hline 3 & complement component 3 & 1.63 & \\
\hline 3AR1 & complement component 3a receptor 1 & & 1.70 \\
\hline \multicolumn{4}{|l|}{ tegrins } \\
\hline IGB2 & integrin, beta 2 & 1.12 & \\
\hline TGAM & integrin, alpha $\mathrm{M}$ & 1.12 & 3.57 \\
\hline
\end{tabular}

KA: the effect of kainic acid refered to genes expression that altered by kainic acid, in comparison to the control group (KA-DMSO versus saline-DMSO group). CUR: the effect for curcumin was determined by genes that altered expression in curcumin-treated epileptic rats, in comparison to the kainic acid treated group (i.e. KA-CUR versus KA-DMSO group). The genes that over-expressed or under-expressed at $p<0.05$.

for the selected genes were largely reproduced although the fold changes were differed (Figure 2). Cell surface molecule, CD74, which was differentially expressed by kainic acid on array analysis, was similarly up-regulated by kainic acid (ACTB and TBP: $z=-1.984, p=0.047$ ). Correspondingly, ITGAM were significantly overexpressed in kainic acid (ACTB: $\mathrm{z}=-2.193, p=0.028$ TBP: $\mathrm{z}=-1.984, p=0.047)$ and curcumin treatment (ACTB: $z=-1.984, p=0.047 ;$ TBP: $z=-2.193, p=0.028$ ). Although the gene expressions were almost similar, qPCR did not show any significant effect on CXCL16 expression by curcumin treatment.

\section{DISCUSSION}

Generally, the number of genes significantly regulated by KA seizure induction was lesser as compared with previous studies using rat model of epileptogenesis, either by kindling ${ }^{17,22}$ or post-SE methods. ${ }^{15,23,24}$ This comparison difference could be attributed to different study designs in microarray platforms, time points, epileptogenesis models, tissue sampling sites and animal factors that have been employed in different studies. ${ }^{13}$ In addition, many transcripts important to central nervous system have low expressions and it is difficult to detect these low abundance transcripts in highly complex tissue. ${ }^{25}$ It had been reported that the sensitivity of Affymetrix Gene Chip array provides approximately $30 \%$ reliable detection in hippocampal tissue. ${ }^{25}$ Hence, the interested genes with fold change less than 2 were also reviewed to prevent overlook on significant genes.

\section{The inflammation and immune response during epileptogenesis}

Inflammation and immune response was the continuation process that significantly up-regulated from acute phase after seizure induction. ${ }^{13,15} \mathrm{KA}$ up-regulated the pro-inflammatory cytokines included IL18 and IFNGR1, which were secreted by activated microglia and played an important role in neuroinflammation. ${ }^{26}$ CD74, a class II major histocompatibility complex that involved in antigen processing and presentation was up-regulated by KA treatment. It also serves as cell surface receptor for the cytokine macrophage migration inhibitory factor and involved in up-regulating the 

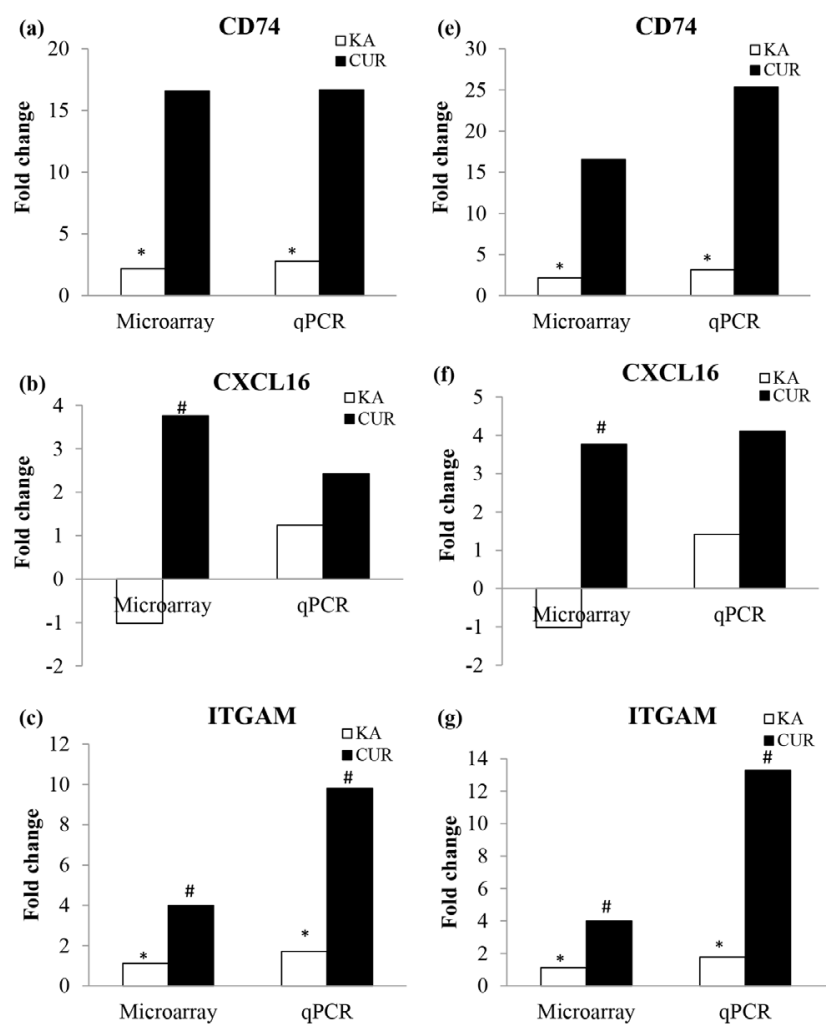

Figure 2: Comparison of expression changes from microarray data and qPCR, with relative to reference genes ACTB $(a, b, c)$ and TBP $(e, f, g)$. The qPCR results showed a large correspondence with microarray expression patterns for selected genes. The fold change showed was compared to control and QPCR data was normalized with reference gene, ACTB or TBP, repectively. KA: kainate induced, DMSO-treated group; CUR: kainate induced, curcumin-treated group. CD74: Cd74 molecule; CXCL16: Chemokine (C-X-C motif) ligand 16; ITGAM: Integrin, alpha M. *: effect of KA, $p<0.05$; \#: effect of curcumin, $\mathrm{p}<0.05$.

expression of cyclooxygenase 2 and prostaglandin $\mathrm{E}_{2}$ secretion in rodent microglia and further activating microglia-associated neuroinflammation. ${ }^{27}$ However, over-activation of prostaglandin receptors was not observed in this study due to the time point of this study involved in latent phase, in which prostaglandin receptors were only activated during acute and chronic phases of epileptogenesis. ${ }^{15}$ A prolonged and sustained inflammation state might ultimately contribute to neuronal injury; therefore, a balance between pro-inflammatory and anti-inflammatory factors is crucial in determining the outcome of the inflammation. ${ }^{26}$ Despite of treatment given, pro-inflammatory cytokines remained to be upregulated in the kainate-induced SE rodents. However, anti-inflammatory cytokines were also over-expressed in addition to pro-inflammatory cytokines by curcumin (IL10RB, CXCL16, and CXCL17). This was not observed in the epileptic group without treatment (KADMSO group). This suggested that curcumin may be involved in activation of these anti-inflammatory factors, which was likely to contribute in counteracting neuroinflammation induced by KA.

Previous studies showed that curcumin modulates the inflammation process by inhibiting the production of pro-inflammatory cytokines, ${ }^{28,29}$ down-regulating the cyclooxygenase- 2 and inducible nitric oxide synthase enzymes ${ }^{29,30}$ particularly those present in edible and medicinal plants, have been reported to possess substantial anticarcinogenic and antimutagenic activities. The majority of naturally occurring phenolics retain antioxidative and anti-inflammatory properties which appear to contribute to their chemopreventive or chemoprotective activity. The mechanistic pathway involved is not elucidated yet, but studies suggested that its antiinflammatory effects might be mediated by suppression of transcription factor nuclear factor-kappa $\mathrm{B}^{30}$ or activation of transcription factor peroxisome proliferatoractivated receptor gamma. ${ }^{31}$ However, in this study, these genes were not significantly changed by curcumin treatment. Interestingly, curcumin have been showed to potentially exert anti-inflammatory activities via up-regulation of anti-inflammatory cytokines, such as IL10RB, CXCL16 and CXCL17.

In current study, curcumin was likely to exert neuroprotective effects through the up-regulation of fractalkine (CX3CL1), the member of the CX3C family chemokines and CXCL16. Studies had demonstrated that fractalkine modulates neuroexcitotoxicity by increasing glutamate uptake through the activity of glutamate transporter $1.32,33$ Besides, fractalkine had been found to enhance postsynaptic GABA receptor sensitivity on serotonin neurons and synaptically stimulate GABA release, thus enhancing the GABAergic activity. ${ }^{34}$ Recent study suggested that CXCL16 is a mediator released from glia cells upon fractalkine stimulation and synergistically promoting neuroprotection with fractalkine against glutamate excitotoxicity. ${ }^{35}$ Hence, this could be the possible mechanistic pathway of curcumin in exerting neuroprotection effects in epileptogenesis.

\section{Cell death during epileptogenesis}

$\mathrm{KA}$ had been reported to induce neuronal cell death via the apoptosis pathway, particularly by activation of caspase- 3 and Bcl-2-interacting mediator. ${ }^{36,37}$ However, the changes of these genes were not observed in the study. This might be attributed to different time points used for sampling. Most of the protease genes are activated at the same time point after SE and mostly peaked at first week..$^{38}$

Interestingly, KA had been showed to down-regulate the expression of NCSTN, which firstly reported in 
this study. Nicastrin plays a role for assembly presenilin/gamma-secretase complexes to mediate Notch signaling and acting as protease in processing the $\beta$-amyloid precursor protein and ultimately, contributing in amyloid $\beta$ proteins production. ${ }^{39,40}$ Nicastrin also suggested contributing in protection against cell death by reducing caspase- 3 activation and the tumor suppressor p53 expression. ${ }^{41}$ This suggests that underexpression of NCSTN was likely attributed to neuronal cell loss induced by KA. However, there is very little known about the role of nicastrin in epileptogenesis. In contrast to KA treatment, NCSTN gene was overexpressed in curcumin treated group. This evidenced curcumin might be contributed in protection against kainate-induced cell loss. However, controversial result was reported for curcumin in an in vitro oncology study, which demonstrated that curcumin down-regulated the expression of NCSTN and other components of gamma-secretase complex, and ultimately induced cell death by reducing the Notch signaling pathway. ${ }^{42}$ This difference might be due to curcumin modulates nicastrin differently on different cells. Hence, further studies are required to confirm the effects of curcumin on nicastrin protein in the brain.

On the other hand, cathepsins, studies have been demonstrated lysosomal proteases were over-expressed during epileptogenesis, with different cathepsins were up-regulated at different time points. ${ }^{38,43}$ Cathepsin $\mathrm{D}$ and $\mathrm{H}$ was found to be up-regulated markedly one week after SE and persisting up to 3 months. ${ }^{38}$ The over-expression of cathepsins (CTSA, CTSD) in curcumin treated group was believed to be induced by $\mathrm{KA}$, but the treatments did not change the expression for these cathepsins. However, in vitro study showed that curcumin has a role in inhibiting cathepsin B and $\mathrm{H}$ in cancerous cells. ${ }^{44}$ The in vivo function of cathepsins in central nervous system is not clearly elucidated. Some studies suggested cathepsin D may involve in the phagocytosis activation of glial cells during central nervous inflammation, ${ }^{45}$ neuronal cell death in kainateinduced seizure, ${ }^{43}$ and possibly indicating early regenerative process in vulnerable neurons in Alzheimer's disease. ${ }^{46}$ Targeting at cathepsins can be the potential targets for treatment of epileptogenesis, but provided the exact role of cathepsins are fully elucidated.

\section{Gliosis during epileptogenesis}

Reactive astrocytes have been showed to play a role in gliosis and contributing to epileptogenesis. ${ }^{47,48}$ The gliosis was occurred at peak at 1 week after SE, particularly activation of inflammatory process. ${ }^{15,47}$ Hence, there was high expression of genes encoding complement components, cytokines and major histocompatibility complexes in both kainate and curcumintreated group. Vimentin (VIM), gene of a marker for reactive astrocytes was significantly up-regulated in KA, but not observed in curcumin-treated group. Vimentin was presented $24 \mathrm{~h}$ after onset of SE, increased markedly in glial cells by $1-3$ weeks, and persisting up to 3 months after SE. ${ }^{47}$ Vimentin had been showed to participate in astrocyte reactivity and inhibit axon regeneration after injury. ${ }^{49,50}$ this finding evidenced that curcumin might have a role in modulating the gliosis during epileptogenesis by targeting in astrocyte-mediated inflammatory pathway.

Although we have highlighted several importance findings on the effects of curcumin treatment on seizure-induced rats, we also recognized other possible limitation of the findings as the effects of curcumin on non-seizure induced rats were not evaluated partly as one of the study arms. This was due to the research proposal was planned according to the available research resources. The treatment arms used in this study is sufficient to answer the planned aims of this study.

\section{CONCLUSION}

Gene expression profiling by using microarray provides an overview of gene regulation related to important processes and functions in kainate-induced rat model of epileptogenesis. By comparing gene expression profiling in animal model with and without pharmacological treatment, it enable the investigation of the molecular pathways associated with pharmacological treatments, as well as identification of potential molecular targets for antiepileptic drugs. Multiple biological processes were involved in kainate-induced epileptogenesis. Inflammation and immune response were the prominent over-expressed processes by KA. In addition, changes in other process, such as cell death and gliosis also involved during epileptogenesis. The alteration on the genes involved could be explored as possible targets to counteract the epileptogenic process. Besides, this study provides novel insights into the mechanisms of curcumin in regulating gene expression in epileptic brain which form the basis for future studies looking into its molecular pathway as an antiepileptogenic agent.

\section{ACKNOWLEDGEMENT}

This study was supported under a grant from Ministry of Education (grant no.: FRGS/1/2012/SKK02/ $\mathrm{UKM} / 02 / 2)$. The authors wish to acknowledge Malaysia Genome Institute for providing the Agilent Bioanalyzer service. 


\section{CONFLICT OF INTEREST}

The authors declare no conflict of interest.

\section{ABBREVIATION}

KA: Kainic acid; TLE: Temporal lobe epilepsy; SE: Status epilepticus; DAVID: Database for Annotation, Visualization and Integrated Discovery; DMSO: Dimethyl sulfoxide; RNA: Ribonucleic acid; CUR: Curcumin; cDNA: Complementary deoxyribonucleic acid; GO: Gene Ontology.

\section{REFERENCES}

1. Loscher W, Gernert M, Heinemann U. Cell and gene therapies in epilepsy-promising avenues or blind alleys? Trends Neurosci. 2008;31(2):62-73.

2. Siegel AM. Presurgical evaluation and surgical treatment of medically refractory epilepsy. Neurosurg Rev. 2004;27(1):1-21.

3. Pitkanen A, Kubova H. Antiepileptic drugs in neuroprotection. Expert Opin Pharmacother. 2004;5(4):777-98.

4. Jacobs MP, Leblanc GG, Brooks-Kayal A, Jensen FE, Lowenstein DH, Noebels $\mathrm{JL}$, in vivo Curing epilepsy: progress and future directions. Epilepsy Behav. 2009;14(3):438-45.

5. Loscher W. Critical review of current animal models of seizures and epilepsy used in the discovery and development of new antiepileptic drugs. Seizure. 2011;20(5):359-68.

6. Morimoto K, Fahnestock M, Racine RJ. Kindling and status epilepticus models of epilepsy: rewiring the brain. Prog Neurobiol. 2004;73(1):1-60.

7. Loscher W, Brandt C. Prevention or modification of epileptogenesis after brain insults: experimental approaches and translational research. Pharmacol Rev. 2010;62(4):668-700.

8. Noor NA, Aboul Ezz HS, Faraag AR, Khadrawy YA. Evaluation of the antiepileptic effect of curcumin and Nigella sativa oil in the pilocarpine model of epilepsy in comparison with valproate. Epilepsy Behav. 2012;24(2):199-206.

9. Mehla J, Reeta KH, Gupta P, Gupta YK. Protective effect of curcumin against seizures and cognitive impairment in a pentylenetetrazole-kindled epileptic rat model. Life Sci. 2010;87(19):596-603.

10. Jyoti $A$, Sethi $P$, Sharma D. Curcumin protects against electrobehavioral progression of seizures in the iron-induced experimental model of epileptogenesis. Epilepsy Behav. 2009;14(2):300-8.

11. Choudhary KM, Mishra A, Poroikov V V, Goel RK. Ameliorative effect of Curcumin on seizure severity, depression like behavior, learning and memory deficit in post-pentylenetetrazole-kindled mice. Eur $\mathrm{J}$ Pharmacol. 2013;704(1-3):33-40.

12. Lukasiuk K, Pitkanen A. Large-scale analysis of gene expression in epilepsy research: is synthesis already possible? Neurochem Res. 2004;29(6):1169-78.

13. Aronica E, Gorter JA. Gene expression profile in temporal lobe epilepsy. Neuroscientist. 2007;13(2):100-8.

14. Slonim DK, Yanai I. Getting started in gene expression microarray analysis. PLoS Comput Biol. 2009;5(10):e1000543.

15. Gorter JA, van Vliet EA, Aronica E, Breit T, Rauwerda H, Lopes da Silva FH, et al. Potential new antiepileptogenic targets indicated by microarray analysis in a rat model for temporal lobe epilepsy. J Neurosci. 2006;26(43):11083-110.

16. Hendriksen H, Datson NA, Ghijsen WE, van Vliet EA, da Silva FH, Gorter JA, et al. Altered hippocampal gene expression prior to the onset of spontaneous seizures in the rat post-status epilepticus model. Eur J Neurosci. 2001;14(9):1475-84.

17. Lukasiuk K, Kontula L, Pitkanen A. cDNA profiling of epileptogenesis in the rat brain. Eur J Neurosci. 2003;17(2):271-9.

18. Becker AJ, Chen J, Zien A, Sochivko D, Normann S, Schramm J, et al. Correlated stage- and subfield-associated hippocampal gene expression patterns in experimental and human temporal lobe epilepsy. Eur J Neurosci. 2003;18(10):2792-802.
19. Racine RJ. Modification of seizure activity by electrical stimulation. II. Motor seizure. Electroencephalogr Clin Neurophysiol. 1972;32(3):281-94.

20. Huang DW, Sherman BT, Lempicki RA. Systematic and integrative analysis of large gene lists using DAVID bioinformatics resources. Nat Protoc. 2009;4(1):44-57.

21. Hosack DA, Dennis GJ, Sherman BT, Lane HC, Lempicki RA. Identifying biological themes within lists of genes with EASE. Genome Biol. 2003;4(10):R70.

22. Gu J, Lynch BA, Anderson D, Klitgaard H, Lu S, Elashoff M, et al. The antiepileptic drug levetiracetam selectively modifies kindling-induced alterations in gene expression in the temporal lobe of rats. Eur $\mathrm{J}$ Neurosci. 2004;19(2):334-45.

23. Motti D, Le Duigou C, Eugene E, Chemaly N, Wittner L, Lazarevic D, et al. Gene expression analysis of the emergence of epileptiform activity after focal injection of kainic acid into mouse hippocampus. Eur J Neurosci. 2010;32(8):1364-79.

24. Okamoto OK, Janjoppi L, Bonone FM, Pansani AP, da Silva AV, Scorza FA, et al. Whole transcriptome analysis of the hippocampus: toward a molecular portrait of epileptogenesis. BMC Genomics. 2010;11(1):230.

25. Evans SJ, Datson NA, Kabbaj M, Thompson RC, Vreugdenhil E, De Kloet ER, et al. Evaluation of Affymetrix Gene Chip sensitivity in rat hippocampal tissue using SAGE analysis. Serial Analysis of Gene Expression. Eur J Neurosci. 2002;16(3):409-13.

26. Ramesh G, MacLean AG, Philipp MT. Cytokines and chemokines at the crossroads of neuroinflammation, neurodegeneration, and neuropathic pain. Mediators Inflamm. 2013;480739.

27. Wang F, Wu H, Xu S, Guo X, Yang J, Shen X. Macrophage migration inhibitory factor activates cyclooxygenase 2-prostaglandin E2 in cultured spinal microglia. Neurosci Res. 2011;71(3):210-18.

28. Abe $\mathrm{Y}$, Hashimoto $\mathrm{S}$, Horie $\mathrm{T}$. Curcumin inhibition of inflammatory cytokine production by human peripheral blood monocytes and alveolar macrophages. Pharmacol Res. 1999;39(1):41-7.

29. Gupta SC, Patchva S, Koh W, Aggarwal BB. Discovery of curcumin, a component of golden spice, and its miraculous biological activities. Clin Exp Pharmacol Physiol. 2012;39(3):283-99.

30. Surh YJ, Chun KS, Cha HH, Han SS, Keum YS, Park KK, et al. Molecular mechanisms underlying chemopreventive activities of anti-inflammatory phytochemicals: down-regulation of COX-2 and iNOS through suppression of NF-kappa B activation. Mutat Res. 2001;480:243-68.

31. Jacob A, Wu R, Zhou M, Wang P. Mechanism of the Anti-inflammatory Effect of Curcumin: PPAR-gamma Activation. PPAR Res. 2007;2007:89369.

32. Catalano M, Lauro C, Cipriani R, Chece G, Ponzetta A, Di Angelantonio S, et al. CX3CL1 protects neurons against excitotoxicity enhancing GLT-1 activity on astrocytes. J Neuroimmunol. 2013;263(1):75-82.

33. Limatola C, Ransohoff RM. Modulating neurotoxicity through CX3CL1/ CX3CR1 signaling. Front Cell Neurosci. 2014;8:229.

34. Heinisch S, Kirby LG. Fractalkine/CX3CL1 enhances GABA synaptic activity at serotonin neurons in the rat dorsal raphe nucleus. Neuroscience. 2009;164(3):1210-23.

35. Rosito M, Lauro C, Chece G, Porzia A, Monaco L, Mainiero F, et al. Trasmembrane chemokines CX3CL1 and CXCL16 drive interplay between neurons, microglia and astrocytes to counteract pMCAO and excitotoxic neuronal death. Front Cell Neurosci. 2014;8:193.

36. Verdaguer E, Garcia-Jorda E, Jimenez A, Stranges A, Sureda FX, Canudas AM, et al. Kainic acid-induced neuronal cell death in cerebellar granule cells is not prevented by caspase inhibitors. Br J Pharmacol. 2002;135(5):1297-307.

37. Shinoda S, Schindler CK, Meller R, So NK, Araki T, Yamamoto A, et al. Bim regulation may determine hippocampal vulnerability after injurious seizures and in temporal lobe epilepsy. J Clin Invest. 2004;113(7):1059-68.

38. Gorter JA, Van Vliet EA, Rauwerda H, Breit T, Stad R, van Schaik L, et al. Dynamic changes of proteases and protease inhibitors revealed by microarray analysis in CA3 and entorhinal cortex during epileptogenesis in the rat. Epilepsia. 2007;48 Suppl(s5):53-64.

39. Li T, Ma G, Cai H, Price DL, Wong PC. Nicastrin is required for assembly of presenilin/gamma-secretase complexes to mediate Notch signaling and for processing and trafficking of beta-amyloid precursor protein in mammals. $\mathrm{J}$ Neurosci. 2003;23(8):3272-7. 
40. Edbauer D, Winkler E, Haass C, Steiner H. Presenilin and nicastrin regulate each other and determine amyloid beta-peptide production via complex formation. Proc Natl Acad Sci U S A. 2002;99(13):8666-71.

41. Pardossi-Piquard R, Dunys J, Giaime E, Guillot-Sestier MV, St GeorgeHyslop P, Checler F, et al. p53-dependent control of cell death by nicastrin: lack of requirement for presenilin-dependent gamma-secretase complex. J Neurochem. 2009;109(1):225-37.

42. Subramaniam D, Ponnurangam $S$, Ramamoorthy $P$, Standing $D$, Battafarano RJ, Anant S, et al. Curcumin induces cell death in esophageal cancer cells through modulating Notch signaling. PLoS One. 2012;7(2):e30590.

43. Hetman M, Filipkowski RK, Domagala W, Kaczmarek L. Elevated cathepsin $\mathrm{D}$ expression in kainate-evoked rat brain neurodegeneration. Exp Neurol. 1995;136(1):53-63.

44. Ravish I, Raghav N. Curcumin as inhibitor of mammalian Cathepsin B, Cathepsin $\mathrm{H}$, acid phosphatase and alkaline phosphatase: a correlation with pharmacological activities. Med Chem Res. 2014;23(6):2847-55.

45. Moon C, Lee T-K, Kim H, Ahn M, Lee Y, Kim MD, et al. Immunohistochemical study of cathepsin $D$ in the spinal cords of rats with clip compression injury. J Vet Med Sci. 2008;70(9):937-41.
46. Cataldo AM, Barnett JL, Berman SA, Li J, Quarless S, Bursztajn S, et al. Gene expression and cellular content of cathepsin D in Alzheimer's disease brain: evidence for early up-regulation of the endosomal-lysosomal system. Neuron. 1995;14(3):671-80.

47. Aronica E, van Vliet EA, Mayboroda OA, Troost D, da Silva FH, Gorter JA. Upregulation of metabotropic glutamate receptor subtype mGluR3 and mGluR5 in reactive astrocytes in a rat model of mesial temporal lobe epilepsy. Eur J Neurosci. 2000;12(7):2333-44.

48. Aronica E, Ravizza T, Zurolo E, Vezzani A. Astrocyte immune responses in epilepsy. Glia. 2012;60(8):1258-68.

49. Menet V, Prieto M, Privat A, Gimenez y Ribotta M. Axonal plasticity and functional recovery after spinal cord injury in mice deficient in both glial fibrillary acidic protein and vimentin genes. Proc Natl Acad Sci U S A. 2003;100(15):8999-9004.

50. Wilhelmsson U, Li L, Pekna M, Berthold CH, Blom S, Eliasson C, et al. Absence of glial fibrillary acidic protein and vimentin prevents hypertrophy of astrocytic processes and improves post-traumatic regeneration. J Neurosci. 2004;24(21):5016-21.

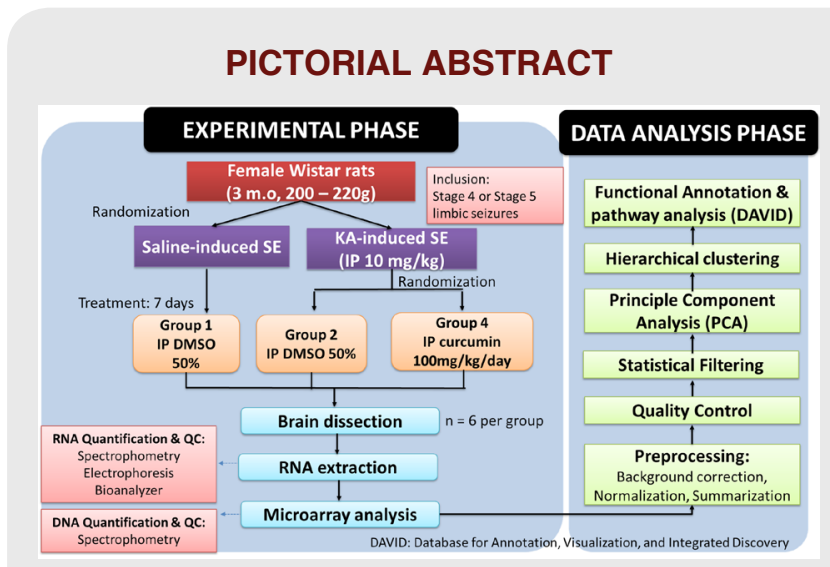

\section{SUMMARY}

- Multiple biological processes were involved during latent phase of kainate induced epileptogenesis, included inflammation and immune system, cell death and gliosis.

- Curcumin was found to be involved in modulating epileptogenic process by up-regulating genes associated with anti-inflammatory cytokines (Il10rb, Cxcl16, Cxcl17) and cell death protection protein (Ncstn).

- Curcumin was likely to exert neuroprotective effects through the up-regulation of fractalkine (CX3CL1), the member of the CX3C family chemokines and CXCL16.

Cite this article: Hui-Yin Y, Ahmad N, Azmi N, Makmor-Bakry M. Curcumin: The Molecular Mechanisms of Action in Inflammation and Cell Death during Kainate-Induced Epileptogenesis. Indian $\mathrm{J}$ of Pharmaceutical Education and Research. 2018;52(1):32-41. 